\title{
A Coronavirus (COVID-19) Triage Framework for (Sub)National Public-Private Partnership (PPP) Programs
}

\author{
David Baxter $^{1}$ and Carter B. Casady ${ }^{2, *(1)}$ \\ 1 Infrastructure Development/PPP Consultant and Steering Committee Member for the World Association of \\ PPP Units \& Professionals (WAPPP), Washington, DC 22312, USA; dbaxter@wappp.org \\ 2 Bartlett School of Construction and Project Management, University College London, \\ London WC1E 7HB, UK \\ * Correspondence: c.casady@ucl.ac.uk
}

Received: 3 June 2020; Accepted: 24 June 2020; Published: 29 June 2020

check for updates

\begin{abstract}
Around the world, countries are struggling to address the immediate and long-term impacts of the novel coronavirus (COVID-19) pandemic on their (sub)national public-private partnership (PPP) programs. Burdened with the real possibility of widespread project failures and constrained budgets, governments are searching for ways to prioritize projects in need of relief and bolster post-pandemic recovery plans. To meet this need, this article conceptualizes a triage system for PPP programs based on five categories: (1) projects without a need for economic stimulus (blue); (2) projects experiencing minor economic/financial losses (green); (3) projects needing temporary/stop-gap support or restructuring (yellow); (4) projects unable to survive without significant economic relief (red); and (5) projects that cannot survive, even with government intervention (black). This research also stresses the importance of launching and sustaining a crisis command center to support PPP triage decisions and encourages PPP stakeholders to collectively craft win-win solutions for post-pandemic recovery efforts.
\end{abstract}

Keywords: coronavirus (COVID-19); public-private partnerships (PPPs) triage; crisis management; resilience

\section{An Unprecedented Battle}

The novel coronavirus (COVID-19) pandemic caught most public agencies at all levels of government off-guard, leaving them ill-equipped to address the immediate and long-term impacts on their (sub)national public-private partnership (PPP) programs. In the United States alone, procurements for several infrastructure PPP projects have already been delayed, put on hold, or cancelled altogether [1]. With uncertainty increasing around demand-risk transit and toll road projects, more project failures are anticipated. States are also projected to face a 30 percent drop in transportation-related revenues (e.g., gas tax) over the next 12-18 months. Combined with sharp declines in sales tax revenue, the fiscal position of state and local governments will continue to deteriorate through at least fiscal year (FY) 2021 [2] and "catch-up" funding mechanisms may be needed for state and local infrastructure development and recovery efforts [3].

Without flexible surge capacity "to scale up and down resources in a fast, smooth, and productive way" [4] (p. 1), many governments, banking organizations, and development institutions still do not fully understand the current strengths and weaknesses of their existing PPP programs. They are, therefore, looking for ways to assess the massive, sudden, and unprecedented impacts of the COVID-19 pandemic on PPP projects and (sub)national programs. More specifically, "a new model to exercise or simulate all phases of multiagency disaster management" is needed, "based on real scenarios, to find 
out strengths and weaknesses of [their PPP] organizations and to improve ... access to all resources" [4] (p. 4). This article thus offers a conceptual triage framework for PPP programs. Borrowing from medical and business triage procedures, we outline several triage heuristics for PPP practitioners. We begin by briefly describing the concept of medical triage. Next, we discuss how medical triage models have been adapted by the private sector into decision-making frameworks. Then, we use both medical and business triage approaches as a template for conceptualizing a PPP triage framework. After reflecting on additional considerations for PPP triage actions, we ultimately conclude by encouraging PPP stakeholders to collectively craft win-win solutions for post-pandemic recovery efforts.

\section{Medical Triage}

Medical triage involves identifying and sorting people most urgently in need of care. Adopted from battlefield medicine, triage procedures assess a patient's health status to determine their relative priority for treatment. In practice, triage is reserved for situations (e.g., wars, natural disasters, pandemics, etc.) when both supplies and staff are limited and care must be rationed [5]. In medical settings, injured or ill patients are typically categorized into various treatment groups based on need and urgency. These groupings generally use the following color scheme to identify priority levels:

1. Blue: patients not in need of urgent medical attention or hospitalization;

2. Green: patients with minor injuries or illnesses (i.e., "walking wounded");

3. Yellow: more serious cases whose lives are not yet threatened;

4. Red: those who will die without immediate treatment, and

5. Black: a fifth category reserved for the deceased, or those with no chance of survival $[5,6]$.

With so many patients becoming critical ill simultaneously, many countries have found it impossible to meet the unprecedented healthcare demands of the COVID-19 pandemic [7]. This has forced doctors to make excruciating triage decisions on who to treat [8]. Although some scholars, such as Ouyang, Argon, and Ziya [9], have recently developed mathematical modeling and analysis techniques to improve intensive care unit (ICU) allocation decisions during periods of high patient demand, many of these triage decisions are often based on heuristics (e.g., age, comorbidities, etc.), which value "saving people with the greatest chance of short-term survival, followed by saving those who, thanks to a relative lack of coexisting conditions, have the greatest chance of long-term survival" [7] (p. 1875); see also [10]. When faced with such ethical dilemmas, many scenarios "will still feel morally untenable, particularly in the face of heightened prognostic uncertainty" and resource scarcity [7] (p. 1875). Nevertheless, rationing is often required in the direst circumstances. The COVID-19 pandemic is no exception. King and Kissoon [11] (p. 1794) stress that, "while research during pandemics is fraught with many obstacles, we must be courageous" and test triage models when the opportunity presents.

\section{Business Triage}

Over time, medical triage approaches have been adapted by the private sector into decision-making frameworks. These frameworks help businesses prioritize organizational goals and resource allocation. In global disasters like the COVID-19 pandemic, business enterprises must face "difficult decisions with regard to allocating limited resources between multiple 'mission-critical' functions" [12] (p. 21). In such times of crisis, business triage methodologies offer a simplified means of decision making based on objective, evidence-based criteria. Using similar categories employed by military and disaster-medical services—i.e., red (essential/critical), yellow (important/urgent), and green (optional/supportive) —-these models identify tiers of service/operational criticality for the long-term health of a company. Crises force businesses to prioritize their essential/critical (red) expenses and relieve obvious "pain points" plaguing the organization. Once these "urgent care" needs are stabilized, other important (yellow) functions can be addressed, followed by auxiliary/supportive capabilities [13]. To determine relative organizational priorities, triage determinations will typically involve: 
1. centralized decision making for consistency, speed, and decisiveness;

2. cataloging sources of funds (e.g., cash, lines of credit, equity infusions, etc.);

3. rapidly identifying economic scenarios;

4. modeling projected impacts;

5. defining non-negotiables (i.e., essential/critical functions);

6. drawing on available levers of leadership (expense reductions; hiring freezes, etc.);

7. determining immediate actions to take [14].

Accepted and understood throughout the organization, these triage procedures ultimately promote business continuity during rapidly evolving and unpredictable events. By identifying the sickest "patients" (i.e., processes) first and quickly stabilizing them, businesses can then prioritize other urgent operations that will need more planning and resources to fix [15].

\section{Public-Private Partnership (PPP) Triage: A Conceptual Framework}

Taken together, both medical and business triage processes offer a useful template for conceptualizing a PPP triage framework in the COVID-19 epoch. Because the likelihood of widespread PPP project failures is all but inevitable, governments will soon face the difficult and unenviable task of triaging PPP projects in their (sub)national programs so they can maximize project survival and kickstart national recovery efforts. Such a "mass-casualty event" will require rapid assessment of the "current health" of PPP projects to determine if they are in a terminal downward trajectory or show signs of resuscitation and recovery.

In this assessment process, government institutions (i.e., PPP units, ministries of finance, treasury units, and other line ministries) may find themselves in almost the same situation as hospital ICUs, facing critical shortages of funding, financing, and material resources to keep their projects functioning. Governments facing such constraints should thus develop "several triage heuristics policies that can potentially be used in practice" [9] (p. 592). For instance, a sophisticated and objective PPP triage system might begin by separating current PPP projects (and candidate projects) into the following categories (see Table 1).

Table 1. Public-Private Partnership (PPP) Triage Framework.

\begin{tabular}{ccc}
\hline Triage Code & Criteria & Action or Priority \\
\hline Blue & $\begin{array}{c}\text { Project without a need for } \\
\text { economic stimulus }\end{array}$ & $\begin{array}{c}\text { Periodically (re)assess project key performance } \\
\text { indicators (KPIs) }\end{array}$ \\
\hline Green & $\begin{array}{c}\text { Project experiencing minor } \\
\text { financial/economic losses }\end{array}$ & $\begin{array}{c}\text { Closely monitor project KPIs for early signs of project } \\
\text { distress/default }\end{array}$ \\
\hline Yellow & $\begin{array}{c}\text { Project needs temporary/stop-gap } \\
\text { support or restructuring }\end{array}$ & $\begin{array}{c}\text { Explore contractual renegotiation procedures and } \\
\text { other conciliation mechanisms }\end{array}$ \\
\hline Red & $\begin{array}{c}\text { Project will not survive without } \\
\text { significant economic relief }\end{array}$ & $\begin{array}{c}\text { Evaluate existing government guarantees and other } \\
\text { opportunities for economic resuscitation }\end{array}$ \\
\hline Black & $\begin{array}{c}\text { Project cannot survive, even with } \\
\text { government intervention }\end{array}$ & $\begin{array}{c}\text { Prepare for contract termination and/or buyout } \\
\text { procedures }\end{array}$ \\
\hline
\end{tabular}

To illustrate, take, for example, the LBJ-managed lanes in Texas. This PPP recorded a 20 percent traffic drop in March due to the COVID-19 pandemic. However, Ferrovial (the private concessionaire) still recorded growth in both revenues and EBITDA across its toll road division. This stronger-than-expected performance led Moody's to revise its outlook on the LBJ PPP from positive to stable and reaffirm its Baa3 rating despite uncertainty about the project's traffic and revenue recovery [16]. Because the liquidity of the PPP is also expected to remain strong, this project would likely be coded in the triage framework as "blue" and only need to be periodically (re)assessed.

A similar performance assessment could also be applied to airport PPPs affected by the COVID-19 pandemic. For instance, passenger numbers at Heathrow Airport have declined by 18.3 percent, and both revenues and EBITDA have fallen 12.7 percent and 22.4 percent, respectively. However, 
since Heathrow "has the necessary resources to continue operating for at least the next 12 months even in the absence of passengers[,] this PPP would be initially coded as "green" (i.e., experiencing minor financial/economic losses) but potentially reclassified as "yellow" if signs of project distress and/or potential default persist [16].

Finally, the COVID-19 pandemic is exacerbating problems plaguing transit projects like the $\$ 2$ billion Purple Line light-rail PPP in Maryland. Already 976 days-more than $2 \frac{1}{2}$ years-behind schedule and $\$ 755$ million (i.e., 37 percent) over budget, Purple Line Transit Constructors (i.e., the joint-venture between Fluor, Lane Construction Corp. and Traylor Bros) is now threatening to walk away from the 36-year PPP. Efforts are currently underway to save this code "red" project, but a failed settlement could add up to a year to the project's schedule, cost millions more, and end in a protracted legal battle. If the parties are going to find a resolution, all will likely need to share in the sacrifice. However, this prospect comes at a particularly bad time for government budgets suffering from tax revenue losses due to the pandemic [17]. Without any relief or new significant funding from Maryland's Department of Transportation, this PPP may ultimately have to be re-triaged as "black" and prepared for contract termination.

Overall, governments (in conjunction with private sector counterparties, consultants, etc.) could begin using this conceptual PPP triage framework to label each "patient" (i.e., project) by sector or specific service offered, develop preliminary damage assessment records (see, e.g., FEMA [18]), identify project triage priorities for economic mitigation, track triage statuses, and identify additional risks associated with context-specific political, economic, and social factors. Categorizing desired outcomes/goals using such a PPP triage model would ultimately ensure limited resource allocation support and maintain national recovery goals.

\section{Additional Considerations for PPP Triage Actions}

Naturally, the utility of any PPP triage framework for decision making, goal prioritization, and resource allocation will depend on a country's institutional capacity and surrounding PPP-enabling environment $[19,20]$. Governments should thus consider launching and sustaining a crisis command center to effectively triage PPP projects [14]. Within this center, one of the first and most important tasks is to separate PPP specialists providing "care" for projects from those making triage decisions. A "triage officer", backed by a team with expertise in PPP preparation, procurement, and management, would make resource allocation decisions and communicate them within their PPP unit, ministry of finance, treasury unit, or other line ministry overseeing a country's (sub)national PPP program. Using revised and recalibrated Value for Money (VfM) assessments, Public Sector Comparators (PSCs), and other PPP screening tools, this triage team would provide economic and commercial rationales for triage decisions rather than quick fixes based on political headwinds. These decisions would then be reviewed regularly by a centralized (sub)national-level monitoring committee to ensure other factors, such as "People First PPP" considerations, project sustainability, and resilience, are given weight in decisions to rescue current PPP projects and reprioritize procurements for future PPPs [21]. Such oversight and governance will ensure countries do not mortgage their futures for ill-conceived, short-term recovery actions.

Finally, the triage framework should be reviewed regularly, as knowledge about the impacts of the pandemic evolves [7]. In this phase, governments may revisit commitments to Sustainable Development Goals (SDGs), see how the pandemic has affected them, and recalibrate national development strategies accordingly. Governments may also wish to (re)consider unsolicited proposals for stalled PPP program initiatives, (re)evaluate the resilience of PPPs to force majeure events, and develop short-, mediumand long-term solutions that strike a balance between investing in the future and reducing costs to survive [22,23]. Overall, post-pandemic recovery efforts should produce new PPP policy guidance and sector-specific models "that may respond, in a logical, consistent, and consultative way, to inevitable changes in policy and the market" [24] (p. 19). 


\section{Conclusions}

Although the "point at which preparedness dissolves into panic will always be context-dependent ... the best outcome of this pandemic would be being accused of having overprepared" [7] (p. 1875). Governments will thus need to begin carrying out extensive and systematic triage assessments of their (sub)national PPPs in order to mitigate the impacts of the COVID-19 pandemic. This article offers an initial conceptualization of PPP triage processes, but hard and decisive decisions still need to be made on both current and planned PPP projects. If PPPs are going to be a central tool for national economic recovery efforts, "trust, shared vision and long-term commitments" are needed so "contracting parties [can] change their adversarial relationships to a more cooperative, team-based approach" [25] (p. 441); see also [26]. Through cooperation, openness, and innovation, PPP stakeholders can collectively craft win-win incentives that maximize opportunities in the face of shared risks [27].

Overall, "[d]ue to the complexity, intensity, and frequency of complex disasters, global leaders in healthcare, government, and business will need to pivot from siloed approaches of decision-making to embrace multidisciplinary and transdisciplinary levels of cooperation" [28] (p. 3838). Doing so will fundamentally change the way transportation, transit, school, and hospital PPPs are designed and operated. Although "a lot of projects have been able to continue, and some, such as hospitals and schools, have even been accelerated[,]" governments still need to provide relief to struggling projects to get them through this tough time [29]. After all, "[p]erfect is the enemy of good, especially during crises when prompt action is required" [14]. Moving forward, much more work still needs to be done to combat COVID-19 and prepare for the next pandemic. Let us not repeat the same mistakes. Instead, let us challenge the complacency of construction management research, "engage in more robust critique and analysis of construction systems, as they are realised in practice[,]" and develop sustainable, resilient, and future-proofed PPPs [30] (p. 1).

Author Contributions: The authors confirm contribution to the paper as follows: conceptualization (D.B. and C.B.C.); writing—original draft preparation (D.B.); writing—review and editing (C.B.C). All authors have read and agreed to the published version of the manuscript.

Funding: Article processing charges (APCs) for open access publication were covered by UCL's Open Access Team. No other external funding was received for this research.

Conflicts of Interest: The authors declare no conflict of interest.

\section{References}

1. Inframation. US P3 Market Summary|May 2020; Inframation-An Acuris Company: New York, NY, USA, 2020.

2. American Association of State Highway and Transportation Officials (AASHTO). State DOTs Feeling the Budgetary Impact of COVID-19. 2020. Available online: https://aashtojournal.org/2020/04/24/state-dotsfeeling-the-budgetary-impact-of-covid-19/ (accessed on 25 May 2020).

3. Casady, C.B.; Geddes, R.R. Asset Recycling for Social Infrastructure in the United States. Public Works Manag. Policy 2020, 25, 281-297. [CrossRef]

4. Khorram-Manesh, A. Flexible surge capacity-public health, public education, and disaster management. Health Promot. Perspect. 2020, 10, 1-5.

5. Harbaugh, K. The Next, Terrible Phase of This Crisis|After Cancellation Comes Triage. 2020. Available online: https://www.theatlantic.com/ideas/archive/2020/03/after-cancellation-comes-triage/608146/ (accessed on 25 May 2020).

6. Barfod, C.; Danker, J.; Forberg, J.; Lauritzen, M.M. The distribution of triage categories and the impact of emergency symptoms and signs on the triage level. Scand. J. Trauma Resusc. Emerg. Med. 2010, 18, 34. [CrossRef]

7. Rosenbaum, L. Facing Covid-19 in Italy-Ethics, logistics, and therapeutics on the epidemic's front line. N. Engl. J. Med. 2020, 382, 1873-1875. [CrossRef]

8. Romeo, N. The Grim Ethical Dilemma of Rationing Medical Care, Explained|How Hospitals Decide Which Covid-19 Patients to Prioritize When Resources Are Scarce. 2020. Available online: https://www.vox.com/ coronavirus-covid19/2020/3/31/21199721/coronavirus-covid-19-hospitals-triage-rationing-italy-new-york (accessed on 25 May 2020). 
9. Ouyang, H.; Argon, N.T.; Ziya, S. Allocation of intensive care unit beds in periods of high demand. Oper. Res. 2020, 68, 591-608. [CrossRef]

10. Farrohknia, N.; Castrén, M.; Ehrenberg, A.; Lind, L.; Oredsson, S.; Jonsson, H.; Asplund, K.; Göransson, K.E. Emergency department triage scales and their components: A systematic review of the scientific evidence. Scand. J. Trauma Resusc. Emerg. Med. 2011, 19, 42. [CrossRef] [PubMed]

11. King, M.A.; Kissoon, N. Triage during pandemics: Difficult choices when business as usual is not an ethically defensible option. Crit. Care Med. 2016, 44, 1793-1795. [CrossRef] [PubMed]

12. Moore, B.; Bone, E.A. Decision-making in crisis: Applying a healthcare triage methodology to business continuity management. J. Bus. Contin. Emerg. Plan. 2017, 11, 21-26.

13. Small Business Network (SBN). A Triage Approach to Operational Efficiency. 2017. Available online: https://www.sbnonline.com/article/triage-approach-operational-efficiency/ (accessed on 23 May 2020).

14. Renjen, P. The Heart of Resilient Leadership: Responding to COVID-19. 2020. Available online: https://www2.deloitte.com/us/en/insights/economy/covid-19/heart-of-resilient-leadership-responding-tocovid-19.html (accessed on 28 May 2020).

15. Cerocke, S. How to Conduct a Business Process Triage. 2015. Available online: https://ncet.org/how-toconduct-a-business-process-triage/ (accessed on 26 May 2020).

16. Fabrizio, A. Ferrovial 1Q20 Toll Road Revenue Up Despite COVID-19; Inframation-An Acuris Company: New York, NY, USA, 2020.

17. Shaver, K. Maryland Likely to Be on the Hook for Millions If It Wants to Save the Purple Line Project, Analysts Say. 2020. Available online: https://www-washingtonpost-com.cdn.ampproject.org/c/s/www. washingtonpost.com/local/trafficandcommuting/maryland-likely-to-be-on-the-hook-for-millions-if-itwants-to-save-the-purple-line-project-analysts-say/2020/06/12/29b40dda-ab39-11ea-a9d9-a81c1a491c52_ story.html?outputType=amp (accessed on 14 June 2020).

18. Federal Emergency Management Agency (FEMA). PDA Pocket Guide; FEMA: Washington, DC, USA, 2020.

19. Casady, C.B.; Eriksson, K.; Levitt, R.E.; Scott, W.R. (Re) defining public-private partnerships (PPPs) in the new public governance (NPG) paradigm: An institutional maturity perspective. Public Manag. Rev. 2020, 22, 161-183. [CrossRef]

20. Casady, C.B. Examining the institutional drivers of Public-Private Partnership (PPP) market performance: A fuzzy set Qualitative Comparative Analysis (fsQCA). Public Manag. Rev. 2020, 1-25. [CrossRef]

21. United Nations Economic Commission for Europe (UNECE). "What are People-First PPPs?"; UNECE International Center of Excellence: Geneva, Switzerland, 2019.

22. Baxter, D.; Casady, C.B. Proactive and Strategic Healthcare Public-Private Partnerships (PPPs) in the Coronavirus (Covid-19) Epoch. Sustainability 2020, 12, 5097. [CrossRef]

23. Gulati, R.; Nohria, N.; Wohlgezogen, F. Roaring out of Recession. 2010. Available online: https://hbr.org/ 2010/03/roaring-out-of-recession (accessed on 28 May 2020).

24. Farquharson, E.; Torres de Mastle, C.; Yescombe, E.R.; Encinas, J. How to Engage with the Private Sector in Public-Private Partnerships in Emerging Markets; World Bank: Washington, DC, USA, 2011.

25. Weston, D.C.; Gibson, G.E., Jr. Partnering-project performance in US Army Corps of Engineers. J. Manag. Eng. 1993, 9, 410-425. [CrossRef]

26. Henisz, W.J.; Levitt, R.E.; Scott, W.R. Toward a unified theory of project governance: Economic, sociological and psychological supports for relational contracting. Eng. Project Organ. J. 2012, 2, 37-55. [CrossRef]

27. Crowley, L.G.; Karim, M.A. Conceptual model of partnering. J. Manag. Eng. 1995, 11, 33-39. [CrossRef]

28. Goniewicz, K.; Khorram-Manesh, A.; Hertelendy, A.J.; Goniewicz, M.; Naylor, K.; Burkle, F.M. Current Response and Management Decisions of the European Union to the COVID-19 Outbreak: A Review. Sustainability 2020, 12, 3838. [CrossRef]

29. Gismondi, A. P3 Projects Moving Ahead Despite Pandemic, Some Accelerated. 2020. Available online: https: //canada.constructconnect.com/dcn/news/projects/2020/05/p3-projects-moving-ahead-despite-pandemic-someaccelerated (accessed on 1 June 2020).

30. Sherratt, F.; Sherratt, S.; Ivory, C. Challenging complacency in construction management research: The case of PPPs. Constr. Manag. Econ. 2020, 1-15. [CrossRef]

(C) 2020 by the authors. Licensee MDPI, Basel, Switzerland. This article is an open access article distributed under the terms and conditions of the Creative Commons Attribution (CC BY) license (http://creativecommons.org/licenses/by/4.0/). 